2. Facts of this second order have been thoroughly established by the important researches of Professor Burdon Sanderson. He says :* ammonia are injected underneath the skin of a guinea-pig, a diffuse inflammation is produced, the exudation liquid of which is found after twenty-four hours to be charged with bacteria." "Other chemical agents", he adds, "will lead to the same results, and always under conditions which preclude the possibility of the introduction of any infecting matter from without."

Elsewhere, $\uparrow$ the same investigator refers to experiments which were made about the same time in order to throw light upon the cause of the appearance of bacteria in certain peritoneal exudations, and to ascertain whether or not their presence was to be considered as "a mere result of the intensity of the peritonitis". He says : "To determine this, experiments were made during the following month (May 1871), which consisted in inducing intense peritonitis by the injection, not of exudation liquids, but of chemical irritants, particularly dilute ammonia and concentrated solution of iodine in hydriodic acid. As regards the ammonia, precautions were taken to guard against contamination by boiling and cooling the liquids, as well as the implements to be used, immediately before injection. In the case of the iodine solution, this was, of course, unnecessary. In every instance, it was found that the exudation liquids, collected from twenty-four to fortyeight hours after injection, were charged with bacteria, whence it appeared probable that the existence of these organisms was dependent, not on the nature of the exciting liquid by which the inflammation was induced, but on the intensity of the inflammation itself."

From the various evidence, more or less fully referred to in the present section, it seems to me legitimate to conclude :

First, that, if we are to be guided by the analogy now dwelt upon as existing between fermentation and zymosis, it would be perfectly certain that the latter process can originate de novo - that is, under the influence of certain general or special conditions, and where specific contagia of any kind are at first absent, though they subsequently appear as resulıs or concomitant products. So that an exclusive theory of "contagion", as the only present cause of communicable diseases, is not supported by experimental evidence.

Secondly, that some contagia are mere not-living chemical principles, though others may be living units.

Thirdly, that, even in the latter case, if the primary contagious action be really due to the living units and not to the media in which they are found, such primary action is probably dependent rather upon the chemical changes or "contact actions" which they are capable of setting up than upon their mere growth and vegetative multiplication.

Fourthly, that, where we have to do with a true living contagium (whether pus-corpuscle or ferment-organism), the primary changes which it incites are probably of a nature to engender (either in the fluids or from the-tissue-elements of the part) bodies similar to itself, so that the infected part speedily swarms therewith. When pus from a certain focus of inflammation comes into contact with a healthy conjunctiva, and therein excites a contagious form of inflammation, no one adopts the absurd notion that all the pus-corpuscles in this second inflammatory focus are the lineal descendants of those which acted as the contagium; and the mode of action may be altogether similar when matter containing bacilli, by coming into contact with a wounded surface, gives rise to splenic fever and the appearance of such organisms all through the body. The old notion about the excessive selfmultiplication of the original contagium is probably altogether erroneous.

Thus, all the distinctive positions of those who advocate a belief in the so-called "germ-theory of disease", or rely upon the exclusive doctrine of a "contagium vivum", seem to be absolutely broken down and refuted. We may give that attention to the appearance and development of independent organisms in association with morbid processes which the importance of their presence demands, but we must regard them as concomitant products, and not at all, or except to an extremely limited extent, as causes of those local and general diseases with which they are inseparably linked.

dantly distributed, similar to those which Mcssr.. Cumin riam and Lewis have figured. Some were bacilli, and some were more like what Coin now distingrishe as vibriones. They were not so abundant as to be always ouid without careful examination; and, on the other hand in the diseased splenic tissue there were a multitude of small acicular crystals, which an inexperienced observer might mistale for motionless organisms. In the lower healthy portion of the spleen no organisms were found.

* Transactions of the P'athulorical Society, $1872, \mathrm{pp} .306-308$.

† Reports of the Medical Officer of the Priz'y Council, etc., new series, No. vi, I875, p. 57 .

\section{ON REDUPLICATION OF THE FIRST SOUND OF} THE HEART.

By PHILIP BINDLEY, M.B.Lond.,

Assistant-Physician to the General Hospital, Birmingham.

IN commenting on reduplication and accentuation of the sounds of the heart, it is necessary, in order that all ambiguity may be avoided, to state at the onset what is considered to be the mechanism of the sounds. Here, however, it is not proposed to enter upon the controversy, but merely to specify that in the following observations the first sound is considered to be caused by tension of the auriculo-ventricular valves, and the second by tension of the semilunar valves.

The fact that a doubling of the first sound of the heart sometimes occurred was known to the older authors; but, in his Lumleian lectures, the late Dr. Sibson propounded a theory, that this reduplication is due to an asynchronous action of the ventricles; and Dr. George Johnson, in the Lumleian lectures for the year 1877, propounds another theory, that it is due to an audible contraction of a dilated and hypertrophied auricle. The condition in which this phenomenon is most frequently observed to exist is an abnormal degree of arterial tension, which is a constant accompaniment of Bright's disease. Briefly, Dr. Sibson's theory is this. In consequence of the greater tension of the arteries, the left ventricle, meeting with an increased resistance, acts more tardily than the right ; hence, a doubling of the first sound. Generally, there is no doubling of the second sound; and this is a difficulty which at first sight appears to stand in the way of accepting the theory of asynchronism. Dr. Sibson met this difficulty by the following explanation. The greater tension, both relative and absolute, of the aorta, causes it to recoil more rapidly than the pulmonary artery and make up in speed what it has lost in time, the two arteries thus delivering their backstroke at the same instant.

Dr. Johnson considers that this explanation raises a more formidable difficulty ; for, if "the greater tension of the aorta, in the cases of renal disease under consideration, enable it to overtake the earlier but less rapidly and forcibly contracting pulmonary artery, it seems obvious that, in the normal condition, when the aorta and the pulmonary artery commence their elastic contractions at the same instant, the much greater tension of the aorta, with its thicker and stronger walls, should react upon and close its valves before those of the more feebly contracting pulmonary artery are closed, and the result would be reduplication of the second sound as a constant and normal condition".

And again, Dr. Johnson says, in reference to cases of emphysema, "In these cases, the increased tension of the pulmonary artery consequent on the obstruction in the lungs can never equal the normal tension of the aorta. However great may be the hypertrophy of the right ventricle in cases of emphysema, the thickness of its wall is never equal to that of the left ventricle. If, then, in accordance with Dr. Sibson's theory of asynchronous ventricular contraction, the right ventricle, in consequence of increased tension in the pulmonary artery, complete its contraction later than the left, and thus cause the doubling of the first sound, the closing of the pulmonary valves must inevitably be effected later than that of the aortic, and the second sound must also be doubled. The reverse, however, is the case. The second sound is single in these cases of emphysema, while the first is distinctly reduplicated."

It is difficult to see the point of Dr. Johnson's criticism. In normal conditions, the pulmonary artery is quite as capable of receiving and reacting against the stroke of the right ventricle as the aorta is against the stroke of the left ventricle. To deny this, amounts to the same thing as saying that a certain degree of elasticity reacting against a given pressure is not exactly equivalent to a greater degree of elasticity reacting against a proportionately greater pressure. It may require a cable to lift a ton, but a thread will lift a pound. The resilience of the pulmonary artery is the exact equivalent in force to the resistance offered by the smaller vessels in the lung, and the thickness and strength of its coats are adequate to the tension to which they are subjected. If, at any time, this natural relation between power and resistance become altered from any cause, then the rapidity of recoil mu,t necessarily be altered too. For instance, if the vis à fronte in the lungs be heightened or diminished, then the pulmonary artery will be correspondingly more tense or less tense, and react more speediily or less speedily, in the same manner as a spring tightlly or sightly wound.

In mitral regurgitation, the blood returning from the lungs meets with an already full auricle, and pulmonary congestion results; the arteries do not discharge their blood with the usual facility, the pulmonary artery becomes distended and its tension at the same time in- 
creased, which causes it to recoil more quickly after the systole of the right ventricle, and, in consequence, give rise to a second sound slightly reduplicated, and accentuated at the second left interspace.

In pulmonary emphysema, there is a destruction of capillaries, which, by diminishing the channels of exit for the blood in the arteries, must lead to increased tension in the pulmonary artery. When this condition of increased tension pertains on the left side, the result is a reduplication of the first sound; the left ventricle, meeting with an increased resistance during its contraction, takes a longer time about it, and does not complete its systole quite so soon as the right; but the second sound is not doubled here, because the tighter aorta recoils more quickly than the less tight pulmonary artery-overtakes it, in factand making up in time what the ventricle lost, the aortic and the pulmonary valves flap back together. In case of emphysema, a precisely similar condition exists on the right side; the right ventricle labours against an increased resistance and occupies more time during its contraction; but the pulmonary artery, being abnormally tense, recoils more quickly, making up in time what the ventricle lost, and the two second sounds are produced at the same moment. Moreover, in emphysema, there is a further cause contributing to the same result; owing to the destruction of capillaries, less blood passes to the left heart and the ventricle does not obtain its full complement; hence, the aorta is not so distended as in the normal state, its tension is reduced, and its recoil less rapid.

Another objection which Dr. Johnson advances against the theory that the reduplication of the first sound depends on an asynchronous contraction of the ventricles, is that the anatomical arrangement of the muscular fibres renders the synchronous contraction a physical necessity. But it must be borne in mind that the wall of the left ventricle is so much thicker than the wall of the right, that a large proportion of the fibres cannot interlace at the septum, and then pass to the right ven. tricle. And there are some facts which would appear to support the theory of asynchronism. In many cases of reduplication of the first sound-especially in thin chests-if the hand be placed on the præcordial region, the cardiac impulse is not felt as a single uniform blow, but the impression conveyed is wave-like, the wave beginning near the sternum, and thence passing outwards to the apex-beat at the nipple. The hand seems to feel the double first sound. Sometimes this can be seen. It may be accounted for by the right ventricle beginning to contract sooner than the left. In a case of chronic Bright's disease, this peculiarity of impulse was well demonstrated by holding the chestpiece of the stethoscope on the lower border of the fourth left cartilage about an inch and a half from the sternum, in such a manner as to allow its larger half to lie upon the intercostal space-the fingers serving the purpose of a hinge. The cardiac impulse was thus communicated to the stethoscope, and the free end (ear-piece) registered the movement quite distinctly, and, of course, owing to the leverage, greatly exaggerated. On watching the motion of the ear-piece, it was observed to have a kind of double beginning, as if, after it had started to move, it suddenly received an additional shock. This double shock seemed to exactly correspond to the double first sound. It may be urged that this is a proof of the contraction of the left auricle. In order to guard against this source of error, advantage was taken of the fact that the impulse of the right auricle could be felt in the third right intercostal space. By holding a quill pen flat on this space-as a lever - the auricular impulse was communicated sufficiently to be visible at the feather end, which was bent so as to lie close to the ear-piece of the stethoscope, when the latter was applied to the fourth space in the way mentioned above. In order to assist the eye in watching the movements, another bit of quill was stuck into the lumen of the stethoscope so as to lie alongside the quill which was registering the contraction of the auricle. The auricular impulse could be plainly seen to precede the double ventricular movement. Thus there was, first, the auricular impulse; second, the first beginning of the ventricular impulse, due to the contraction of the right ventricle having begun; third, the second beginning of the ventricular impulse, due to the later contraction of the left ventricle. The heart was beating fiftyeight to the minute; and the reduplication of the first sound was remarkably distinct. I hope shortly to be able to contrive a method by which these movements may be collected together upon the revolving drum of a cardiograph.

The double sound heard at the commencement of the ventricular systole in cases of arterial tension, has been consistently spoken of as reduplicated first sound; and it must be admitted that each segment does very closely resemble the normal first sound of the heart, so closely, indeed, that all observers, previously to the announcement of Dr. Johnson's theory of auricular contraction, must have fallen into the fallacy, if Dr. Johnson's theory be correct, of having mistaken the sound of a contracting auricle for that produced by one of the auriculo- ventricular valves. The two divisions of a double first sound also closely resemble one another in character, though not in loudness and distinctness; for there can be no doubt that the mitral valve closes with greater vigour, and hence produces louder vibrations than the tricuspid ; that is to say, a larger proportion of the first sound is generated in the left than the right heart. On auscultating the heart of a patient in whom there is undue tension of the systemic arteries, if the reduplication of the first sound be fairly marked, it is not difficult to determine that the second first sound is louder than the first first sound; whereas in cases of emphysema, where the tension is in the pulmonary system, it is the first first sound which is louder. This difference may be represented graphically thus:

shews the sounds in systemic tension, with the accent on the second
half; and sounds in pulmonary tension, with the accent on the first half.

The following case may be instanced as illustrative of the point in question. A man was suddenly seized, while walking along the street, with dyspnœa, which, in less than half an hour, when he was admitted into the hospital, had amounted to the extremest orthopnœa. He soon began to expectorate thin, watery, rusty, very frothy sputum. Percussion showed both the right auricle and ventricle to be greatly distended, and they could be felt pulsating to the right of the sternum. There was marked epigastric pulsation. Owing to the noises produced in the lungs, and the turbulent movements of the thorax, the heart could not be properly examined. In a few hours, however, the urgency of the symptoms subsided somewhat, and then it was found that the first sound was most distinctly reduplicated, and that, of the two first sounds, the first division was plainly the louder.

The man gradually recovered, and in about a fortnight the epigastrium had ceased to pulsate ; the reduplication of the first sound had disappeared, and the right heart had resumed its normal dimensions; there were no murmurs. If Dr. Johnson's theory be correct in this case, the contraction of the distended right auricle must have caused the first division of the double sound; but can it be supposed that a single dilated auricle in contracting could produce a sound which so nearly resembled an ordinary first sound as to have been mistaken for one-a sound louder than that caused by the systole of both the ventricles together, especially when it is remembered that in health both the auricles contracting together produce no sound at all, or so slight an one that it is totally disregarded ?

A comparison is made by Dr. Johnson between the rhythm heard on the one hand in the cantering triple friction sound-the first division of which is caused by lymph on the surface of the auricle-and the rhythm heard, on the other hand, in cases of reduplicated first sound; the single second sound here causing the last of the triplet. In reply, it may be said that this rhythm supports the theory of asynchronism quite as much as it does the theory of auricular contraction; the "rat-tat-tat" would exactly represent the closure of tricuspid and mitral valves, followed by the semilunar ; the only question to decide being, with what point in a cardiac revolution does the " rat" coincide. The experiment mentioned above certainly does not tend to show that it coincides with the auricular contraction.

Does the contraction of the auricle afford a satisfactory explanation of the first division of the reduplicate sound in a heart where there are no valvular lesions, and when no deposit of lymph has taken place on its surface? Any sound that is produced must be the result of one of the following causes. I. The rubbing of the smooth auricle against the smooth pericardium, of course, can have nothing whatever to do with it, for the much stronger rubbing of the ventricles, which is so often sufficient to give rise to a "white patch", does not cause any sound. 2. If the contraction of the muscular wall of the auricle produce the sound, which is ofen very loud, and always resembles a normal first sound, it might fairly be anticipated that in healih, by careful attention, it would be possible to detect some indica. tion of a sound of similar rhythm preceding the first cardiac sound. Dr. Johnson says, "We have positive evidence of sound resulting from auricular systole. . . As a result of constriction of the mitral orifice, we have the now well known presystolic ... murmur". It cannot be contended that any part of the sound which is heard accompanying this lesion of the mitral valve is caused by the muscular substance of the auricle. The murmur is due entirely to the condition of the valve, just as the murmur in mitral regurgitation is due to the condition of the valve, and not to the muscle of the left ventricle. 3. The third element, which it has been maintained might give rise to sound, is the impact of the blood from the auricle against that in the ventricle. It is impossible to discuss this now, for it cannot be treated of in a few lines. Cases are frequently seen, without any albuminuria, in which arterial tension and reduplication of the first sound are very marked. 
My attention was first called to them by Dr. Wade, and I am indebted to him for kindly allowing me to make reference to them here. A number of these cases were treated by Dr. Wade with weak alkaline solutions, as recommended by him in a recent number of the Practitioner (April 1877). The rapid improvement was very remarkable ; but what I wish especially to refer to is the changes that took place in the circulatory system. The arterial tension soon diminished, and the reduplication gradually became less, until at last a stage was reached when it required some care to determine positively whether or not it was present at all. If the auricular contraction were the cause of this reduplicate sound in these cases, then it is necessary to suppose that, as the arterial tension passed off, the auricular systole was followed more and more quickly by that of the ventricle, till at length the time between the two systoles was reduced to nothing. But it is known that the one occurs about one-tenth of a second before the other in a heart beating sixty to the minute.

\section{CHEIRO-POMPHOLYX.}

By JONATHAN HUTCHINSON, F.R.C.S., Senior Surgeon to the London Hospital, etc.

I HAD certainly hoped that all personal discussion between Dr. Tilbury Fox and myself as to "priority of observation" was long ago at an end. The facts were very fully put before the profession, and might well have been left to its decision. After the expiration of a year, however the subject is reopened, and $\mathrm{Mr}$. Tweedy has been induced to forward to the JOURNAL his record of a conversation with me which occurred as long ago as 1873 . The publication of statements made in conversation is always of questionable propriety, and especially so when the interval is long. Memories are treacherous; and, where the parties concerned differ, it is impossible to decide. Now, although I do not dispute Mr. Tweedy's verbal accuracy, my memory as regards the the general bearing of what passed on that occasion is different from his. His letter appears to me to imply (although in this I may be mistaken) that at the date referred to $I$ asked him about the disease in question, it being at the time comparatively new to me. The conversation took place at my desk at the Moorfields Ophthalmic Hospital. I cannot, be quite certain, but I believe that a case which was present suggested it. I described to Mr. Tweedy, as I had done a hundred times before to others, the peculiar disease which I then named "relapsing bullous eruption on the hands", and for which I then proposed that of cheiro-pompholyx. I was just as familiar with the features of that disease then as I am now; and, if I asked Mr. Tweedy, as he says I did, if he knew it, the question was not put in the search of information respecting it. Mr. Tweedy suggested to me that it was the same disease which Dr. Tilbury Fox called dysidrosis and, after a remark or two as to the etymology of that word, I said that my malady had nothing whatever to do with sweating. Mr. Tweedy said nothing in defence of the dysidrosis theory. On the contrary, I quite understood that he did not support it ; and there, so far as Mr. Tweedy and myself were concerned, the matter ended. I subsequently, as I have previously stated, received a courteous letter from Dr. Fox, inviting me to read his writings on dysidrosis. This, I regret to say, I never did.

Let me just add that it was the theory involved in the name dysidrosis which prevented me from ever realising the possibility that Dr. Fox had really described the same malady which had so much interested me. felt so confident that my "relapsing bullous eruption on the hands" had nothing to do with impeded sweating, and that so definite and wide a term as "dysidrosis" must comprise much more than this curiously local malady, that I never gave the subject the attention which it ought to have claimed. May I suggest, further, that this constitutes a strong objection to the use of the term? I have no desire to prejudge the question as to the anatomical site of the fluid in the sagograin. It is possible, after all, that that fluid is sweat. We must wait for evidence. But meanwhile it is not, I submit, convenient to designate the disease as if its nature were established, nor to use a term which is ttymologically applicable to much more in exclusive reference to one local and clinically very peculiar form. If future investigation should show that in cheiro-pompholyx the initial lesion is, as Dr. Fox and Mr. Tweedy think, a distended sudoriparous duct, still it will remain only one variety of dysidrosis. Names based upon a single physiological hypothesis are seldom appropriate to maladies which present us with a complex group of clinical peculiarities. When it is wished to recognise such groups of symptoms by a name, it seems it wished to recog to use one which is comparatively meaningless. As such, I still prefer the one which I proposed; and, as a further reason for continuing to use it, may state that I still agree with Dr. Robinson of New York, Dr. Thin, and others, in believing that cheiro-pompholyx has nothing to do with dysidrosis.

It appears to me that, since the publication of Dr. Robinson's able paper, the proof of the matter is not difficult to come at. If Dr. Fox can demonstrate that there is a bullous eruption on the hands, the fluid of which, in the earliest stage, is acid and does not coagulate, many of us will believe that dysidrosis extremitatum is a reality.

\section{OBSTETRIC MEMORANDA.}

\section{CONGENITAL UMBILICAL HERNIA.}

I ATTENDED Mrs. McK, aged 44, in her eleventh confinement, on November 9th, 1875, when she was delivered of a small female child. It appeared to be healthy and otherwise well formed, with the exception of a small conical hernial projection into the umbilical cord. The convolutions of the bowel could be distinctly seen through the cord. The child died on the sixth day, from what I considerd to be peritonitis. Whilst Mrs. McK. was sitting before the fire shortly prior to the birth of the child, the waters suddenly escaped, and she remarked to me on my arrival as to their great quantity.

This deformity is one which we should expect to be of comparative frequency, when we consider the development of the fotus from an embryological point of view. I think this will be borne out by notices of cases in the various authorities on deformities. Vrolik has an illustration of this deformity in his beautiful Atlas (Tabula ad illustrandam Embryogenesin), and A. Förster, in his short but complete work (Die Missbildungen der Menschen), has two diagrams. J. F. Meckel (Handbuch der pathologischen Anatomie) describes a number of cases, in some of which the liver, stomach, and part of the intestines were contained in the hernial sac.

According to M. Vrolik (Cyclopadia of Anatomy), this deformity is caused by an arrest of development at that stage in which a part of the viscera is contained in the sheath of the umbilical cord. He also states that the viscera lying in it are always in an imperfect condition. $\mathrm{He}$ mentions that there were only four cases in which the life of the malformed child lasted for any time after birth, in the case of Van der Voort for eight, and in that of Ribko for twelve months.

According to some authorities, excess of the liquor amnii is a cause of deformity ; but whether it be or not, it is impossible to judge from one case. Its modus operandi may be conceived from its pressing on the abdominal walls, and thereby protruding the viscera. It will likewise be seen that the mother was a multipara, and, according to J. G. St. Hilaire (Histoire des Anomalies, tome iii), deformities occur more frequently in them than in primiparæ; and, in my own short experience, 90 per cent. have been in multiparæ, the other 10 per cent. occurring in the somewhat exceptional case of an unmarried primipara.

\section{William Sneddon, M.D., Beith, N.B.}

\section{SUDDEN DEATH THREE WEEKS AFTER DELIVERY FROM THROMBOSIS OF PELVIC VEINS, WITH EMBOLISM AND OBSTRUCTION OF} PULMONARY VESSELS.

S. W., AGED 27, a fair somewhat delicate woman, living about two miles from my residence, was delivered of her third child on Novem. ber 24th. The labour was natural and the placenta readily detached. She progressed satisfactorily, and was seen up to the tenth day. On December 19th, between 9 and ro A.M. I was summoned in haste to see her; but on arrival found her dead. On inquiry, it appeared that, on December 16th, she had complained of pains, supposed to be rheumatic, in the joints, especially the left hip and in the legs; she was said to have been feverish and to have sweated a good deal. She then had cough and shortness of breath. On the morning of her death, on coming downstairs, she was seized with sudden and intense dyspnœe, complained of pain in the region of the heart, and shortly expired.

I made a post mortem examination on the 2 Ist, and found both lungs, especially the upper lobes, much congested, with here and there extra. vasations of dark coagulated blood in their substance. The left lung was bound down by old adhesions. The branches of the pulmonary artery were filled with reddish.brown friable coagulum. In the right ventricle was a cylindrical partly decolorised firm yet friable clot. The veins of the broad ligament, on the left side, and the trunks of the internal and common iliac veins of the same side, were filled with a coagulum of similar character. In the trunk of the right ovarian vein, just before its junction with the inferior vena cava, was a coagulum of the same character as those before mentioned. The vena 